\title{
Morphological Study on the Tongue of Prenatal Goat (Capra hircus)
}

\section{Prabhakar Kumar, MM Farooqui, Ajay Prakash, Varsha Gup- ta, Sri Prakash Singh and Archana Pathak}

Department of Anatomy, College of Veterinary Science \& Animal Husbandry, DUVASU, Mathura

Received March 2015, accepted for publication April 2015

\section{Abstract}

The study was conducted on the tongue of 18 goat foeti which were divided into three groups viz. Group I (below 50 days of gestation), Group II (50-100 days of gestation) and Group III (100 days of gestation to full term) containing 6 foeti each to record the developmental changes in the tongue and its papillae. The size and weight of tongue increased with the advancement of age. Impressions of palatine ridges were visible on the dorsal surface of apex in all the groups. The fungiform papillae were first observed on $49^{\text {th }}$ day of gestation where as circumvallate papillae without surrounding trench were evident by 69 days of gestation. The numbers of circumvallate papillae were found to be $16-17$ on either side with prominent surrounding moat in the tongue of full term fetus.

Keywords: Tongue, Morphology, Goat, Foetus, Lingual Papillae.

\section{Introduction}

Goat (Capra hircus) provides animal protein in the form of meat, milk to human being and slaughter byproducts skin and fibers as raw material to leather industry. Goat farming provides employment opportunity to landless laborer and marginal farmers and thereby contributes in rural livelihood security. There are about 23 descript and non descript breed are found in India. The tongue is highly mobile muscular organ of digestive system for prehension (Dyce et al., 2010), mastication and deglutination (Nickel et al.,1979). In addition it has significant role as organ of taste, cleaning of skin and hair coat. The tongue is situated partly on the floor of the buccal cavity and partly in the anterior wall of the oral part of the phar$\mathrm{ynx}$. The dorsum of tongue is provided with projections of mucous membrane called papillae, disseminated on the lingual surface. Documentation of normal embryonic and fetal development is necessary to understand consequences of harmful influences at 
Prenatal morphology of goat's tongue

various stages of development (Evans \& Sac, 1973). Thus, the development of tongue in goat deserves greater attention during prenatal life. Therefore, the present study was designed to gain thorough knowledge of normal morphogenesis of tongue at different stages of gestation. The result obtained will provide basic data about the morphological features of the tongue at various stages of development in prenatal goat.

\section{Material and Methods}

The study was conducted on the developing tongue of 18 goat embryos/foeti of either sex which were collected from goat embryos/foeti of different gestational age. The material was collected from local slaughter house, dystokia and the aborted cases from clinics and farms. Embryos/foeti were divided into 3 groups viz. Group I (below 50 days of gestation), Group II (50-100 days of gestation) and Group III (100 days of gestation to full term) containing 6 foetii in each. After weighing the foeti with digital monopan balance the approximate age of embryos/foeti was estimated by using formula derived by Singh et al., (1979) in goat after interpolation of formula given by Hugget and Widdas (1951) in mammals. The morphological features of tongue were recorded using stereo-zoom microscope and dissecting microscope.
Kumar et al.

\section{Results and Discussion}

In all three groups, the tongue comprised of three parts the cranial apex, middle body and the caudal root (Fig.1). The free rostral part, the apex was spatula shaped presented dorsal and ventral surfaces facing the palate and the floor of the mouth cavity respectively, as reported in goat foetis (Dar et al., 2014). Impressions of palatine ridges were very faint in first group and gradually became evident from 49 days onward (Fig. 2). The ventral surface of tongue was connected with floor of mouth with a fragile fold of mucous membrane in first group and in later stage, this fold became thickened due to increase in its width. It was more prominent in the tongue of group III. The body constituted the bulk of the organ. The body was narrow in the beginning and gradually increased in width and thickness, on reaching towards apex it became narrower. The root was the last and the shorter part of the tongue lied caudal to the body. The root of the tongue slopes caudo-ventrally toward the base of the epiglottis.

At 43 days of gestation a median sulcus was noticed on dorsal surface of body of tongue which extended towards apex and disappeared just before the begining of apex (Fig. 2). Arey (1966) stated that the tongue develop from paired lateral swellings of first branchial arches which fused in the later stages of gestation and the third median triangual tubercular impar. At this stage the surface of 
tongue was smooth and lingual papillae could not be observed neither by naked eye nor by stereozoom or dissecting microscope. Similar findings were reported by Dar et al. (2013) in goat foeti. By 49 days of gestation few developing fungiform papillae were observed on dorsolateral aspect of apex and body (Fig. 3), as noticed in sheep at $50^{\text {th }}$ days of gestation (Mistretta and Haus, 1996). However, Dar et al. (2013) observed these papillae on 82 days of gestation in goat foetii. The appearance of fungiform papillae has been recoreded in human foti at $9^{\text {th }}$ week of gestation (Arey, 1966). Igbokwe and Okolie (2009) reported that tongues of about 50-day old goat foetus had epithelial thickenings on the dorsum and in the apex of the tongue which might be early rudiments of some lingual papillae.

In group II at 61 days of gestation large number of filiform papillae were found all over the body and apex. Parmar et al. (1999) couldnot observe these papillae during prenatal period in goat foetii. However, Arey (1966) observed filiform papillae in human foteii of 11 weeks. At this stage round, convex, mushroom-like fungiform papillae distributed among filiform papillae and were more concentrated around the tip of the tongue and on cranio-lateral margin. At this stage, few developing circumvallate papillae were also noticed on caudolateral aspect of body. By 69 days of gestation 3-4 developing circumvallate papillae without surrounding trench were evident on either side (Fig. 4). Verma et al. (2011) also observed the circumvallate papillae in buffalo foetii at 77 days of gestation. The earlier appearance of vallate papillae in the present study might be due to species and gestation period differences. Shawulu et al. (2012) noticed circumvallate at 12-13 weeks of gestation in Sahel Goats. These authors further mentioned that microscopically these papillae were encircled by vallums. By 90 days of gestation large number of filiform papillae were distributed all over body and apex, and the fungiform papillae were distributed among the filiform papillae. At this stage 1213 circumvallate papillae arranged in two rows on caudao-lateral aspect of body were found on either side. Parmar et al. (1999) observed 3-5 circumvallate papillae in group II. At 92 days of gestation there was a ridge on the dorsal aspect of body, which was extended towards apex however it was grooved only on the body. At 98 days of gestation, the body was raised posteriorly representing the development of torus linguae rostral to which there was a transverse groove representing lingual fossa. Parmar et al. (1999) reported that torus linguae and transverse lingual fossa started to appear after $10 \mathrm{~cm} \mathrm{CRL} \mathrm{and} \mathrm{was} \mathrm{well}$ defined after $20 \mathrm{~cm}$ CRL in goat foetus. Sarma et al (2003) opined that the torus linguae could be a compensation for the reduced masticatory mechanism in goats owing to the ab- 
Prenatal morphology of goat's tongue

sence of the upper incisors.

In group III, from 107 days old to full term foetii, the apex was spatula shaped which was slightly notched in the midline. Mushroom like fungiform papillae were distributed at the dorsal aspect, as well as on lateral edges. Body was well developed with mushroom like fungiform papillae on it. Hemram and Ray (2009) observed fungiform papillae scattered among the filiform papillae over the entire dorsum in Bengal Goat and Garole Sheep. One distinct ridge was observed extending from region of vallate papillae almost upto the mid of apex. At this stage the number of circumvallate papillae were similar to previous age but the surrounding trenching was prominent comparatively.

In 134 day old foetus, filliform papillae were distributed all over the tongue including the lateral edges. The tip appeared rough to touch as compared to body and root. Mushroom like fungiform papillae were distributed at the tip on dorsal as well as on lateral edges. Body was well developed with button like fungiform papillae. Those papillae at the lateral edges were larger as compared to those on dorsum of the tongue. Vallate papillae were 15 on right side and 16 on left side (Fig. 5). Parmar et al. (1999) observed 1115 in group III on the lateral sides of the cuadal part of dorsum of tongue and were arranged in 2-3 rows. At full term the number of circumvallate pa-
Kumar et al.

pillae were found to be $16-17$ on either side with prominent surrounding moat. Habel (1975) reported 8 to 17 vallate papillae arranged in 2 rows in goat during postnatal period. The conical papillae were observed rostral and dorsolateral to the torus lingua. The lenticular papillae were located as a zone of papillae on the middle part of the torus lingua (Fig. 5). This result was in agreement with the observation of Parmar et al. (1999).

\section{Conclusion}

The study has described the morphological features of tongue at different gestational age in goat foeti. The location, spatial distributions and shape of lingual papillae observed in the study. Fungiform papillae were the first lingual papillae observed in this study (49 days). Circumvallate papillae was first observed at 69 days of gestation and its number varied between 16-17 at full term.

\section{References}

Arey L. B. (1966). Developmental Anatomy - A text book and laboratory manual of embryology. 7th ed. Philadelphia and London,W.B. Saunders Company.

Dar Y., Sarma K. and Devi J. (2013). Studies on gross morphological development of the tongue in goat foetii (Capra hircus). Ruminant Science, 2(2): 175-178. 
Prenatal morphology of goat's tongue

Dyce K.M., Sack W.O. and Wensing C.J.G. (2010). Textbook of Veterinary Anatomy. 4 th ed. Philadelphian: W. B. Saunders Comp.

Evans H. E. and Sack W. O. (1973). Prenatal development of domestic and laboratory mammals. Zbl. Vet. Med.(c) Anatomia Histologia Embryologia, 2 : 11-45.

Habel R.E. (1975). Sisson and Grossman's The Anatomy of the Domestic Animals. Eds: R Getty, Vol 1. $5^{\text {th }}$ Edn, WB Saunders Co, Philadelphia, pp 861-915.

Hemram S. and Ray S. (2009) .Comparative anatomical study of tongue in Black Bengal goat and Garole sheep. Journal of Interacademicia, 13(3) : 311-314.

Hugget A. St. G. and Widdas W.F. (1951). The relationship between mammalian foetal weight and conception age. Journal of Physiology, 114 : 306-317.

Igbokwe C.O. and Okolie C. (2009). The Morphological Observations of some Lingual Papillae in the Prenatal and Prepuberal Stages of Red Sokoto Goats (Capra hircus). International Journal of Morphology, 27 (1): 145 150.

Kumar P., Suri S. and Gahlot P.K. (2008). Comparative morphological and morphometrical study on the
Kumar et al.

tongue of sheep and goat. The Indian Journal of Field Veterinarians, 4(2): 33 -35 .

Mistretta C.M. and Haus L .F. 1996. Temporal and spatial patterns of tenascin and laminin immunoreactivity suggest roles for extracellular matrix in development of gustatory papillae and taste buds. Journal of Comparative Neurology, 364:535-555.

Nickel R., Schummer A. and Seiferle E. (1979). The viscera of the domestic mammals. $2^{\text {nd }}$ edn, Verlag Paul Parey, Berlin, Hamburg. pp: 8185.

Parmar M. L., Malik M. R. and Taluja J. S. (1999). Morphology of tongue in goat foetuses. Indian Journal of Animal Science, 69: 79-81.

Sarma K., Goswami R.N., Kalita S.N., Baishya G. and Devi J. (2003). Morphogenesis of tongue in cross bred pig foetuses. Indian Journal of Animal Science, 73:1029-30.

Shawulu J.C., Kwari H.D. and Abgyal A.Y. (2012). Pre-Natal Growth of the Tongue and Development of the Lingual Papillae in Sahel Goats (Capra hircus). Agricultural Journal. 7(1): 5-9.

Singh Y., Sharma D.N. and Dhingra L.D. (1979). Morphogenesis of the testis in goat. Indian Journal of Animal Science, 49(11): 925-931. 
Verma D., Uppal V., Bansal N. and Anuradha (2014). Differentiation and Development of Fungiform Papillae in
Buffalo Tongue. Indian Journal of Veterinary Anatomy 26 (1): 7-9.

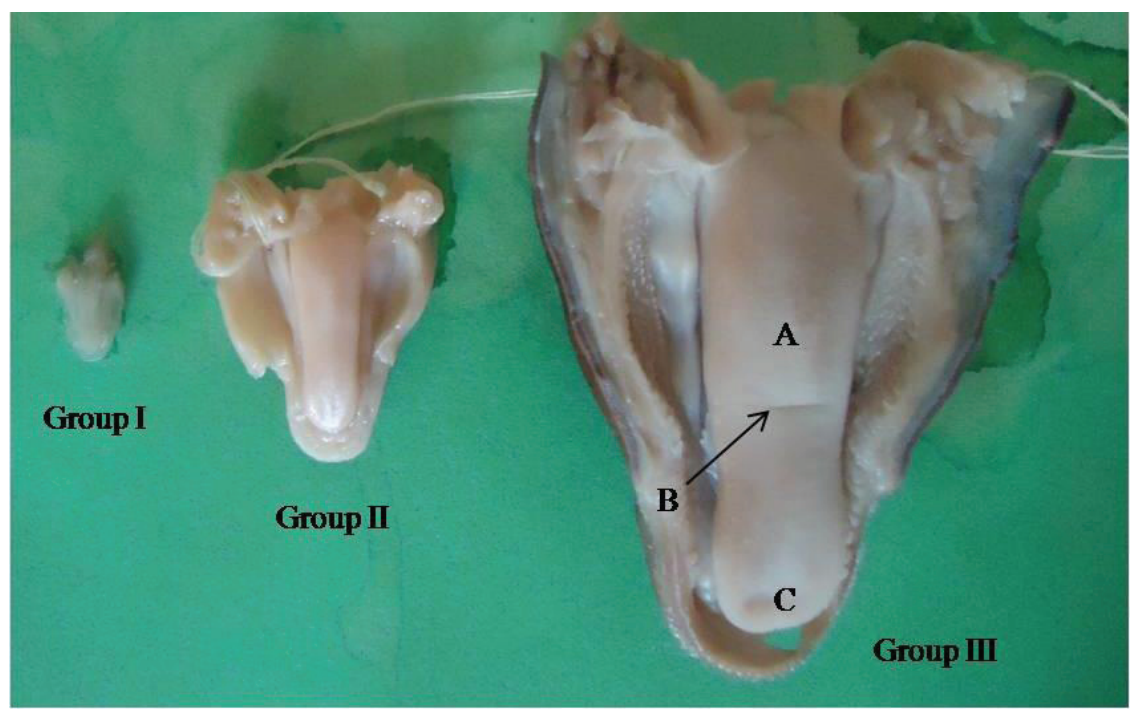

Fig (1): Photograph of tongue of goat foetus of group I, II \& III showing torus linguae (A), lingual fossa (B) and apex (C)

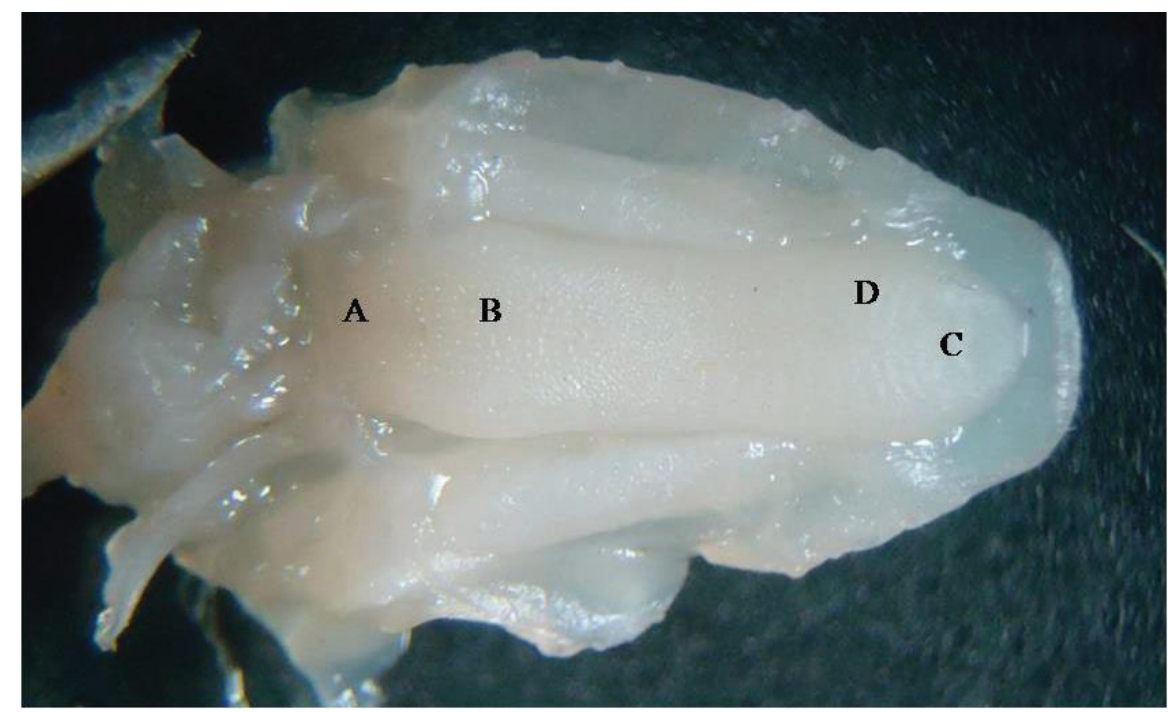

Fig (2): Stereo-zoom microscope photograph of tongue at 43 days of gestation showing: root $(A)$, body $(B)$, apex $(C)$ and impressions of palatine ridges (D) 


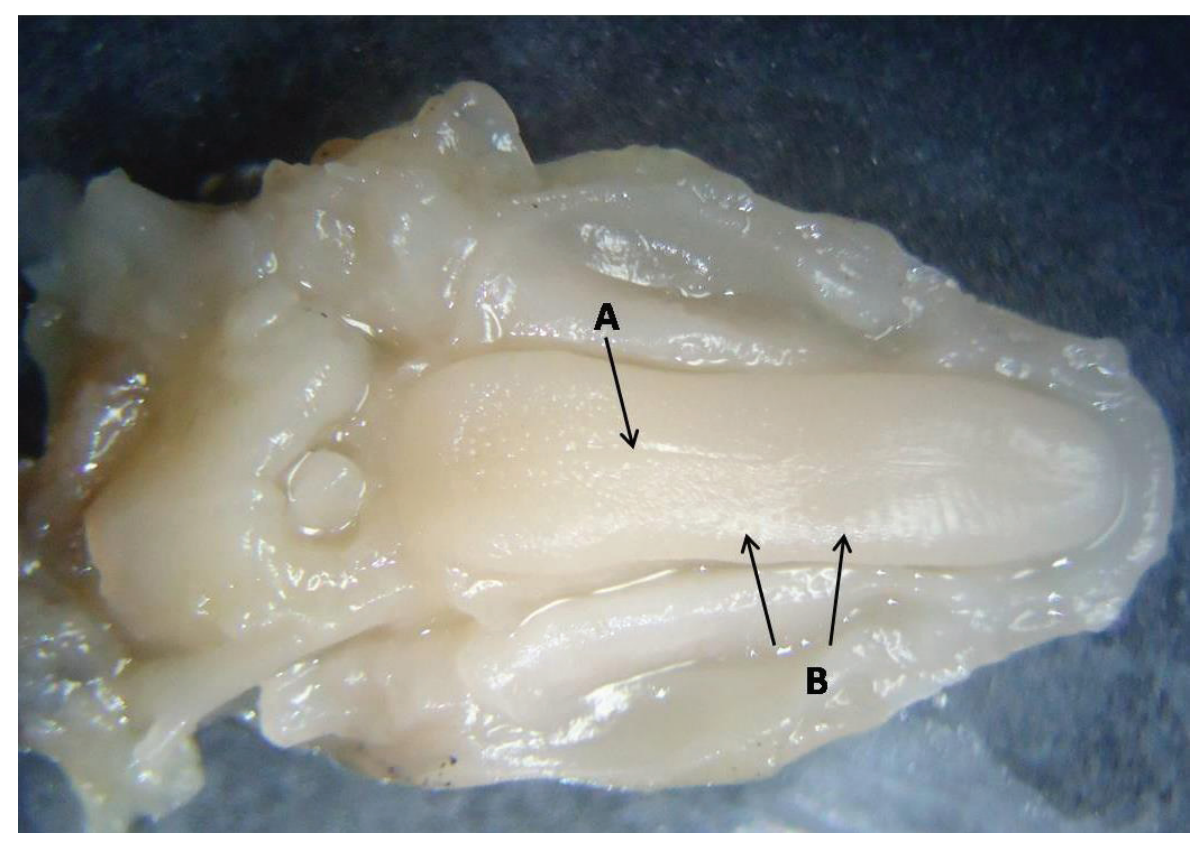

Fig (3): Stereo-zoom microscope photograph of tongue at 49 days of gestation showing median sulcus $(A)$, fungiform papillae $(B)$

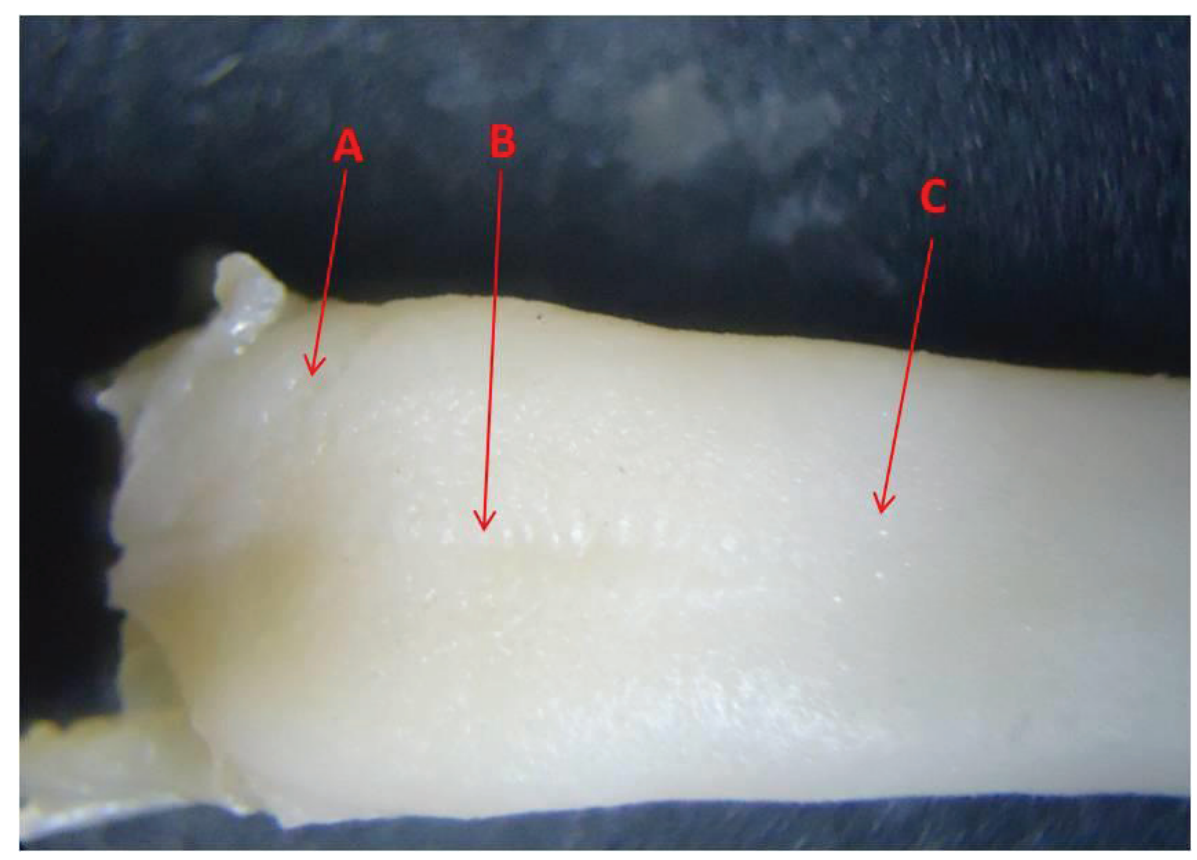

Fig (4): Stereo-zoom microscope photograph of tongue at 69 days of gestation showing developing circumvallate papillae $(A)$, median sulcus $(B)$ and fungiform papillae $(C)$ 


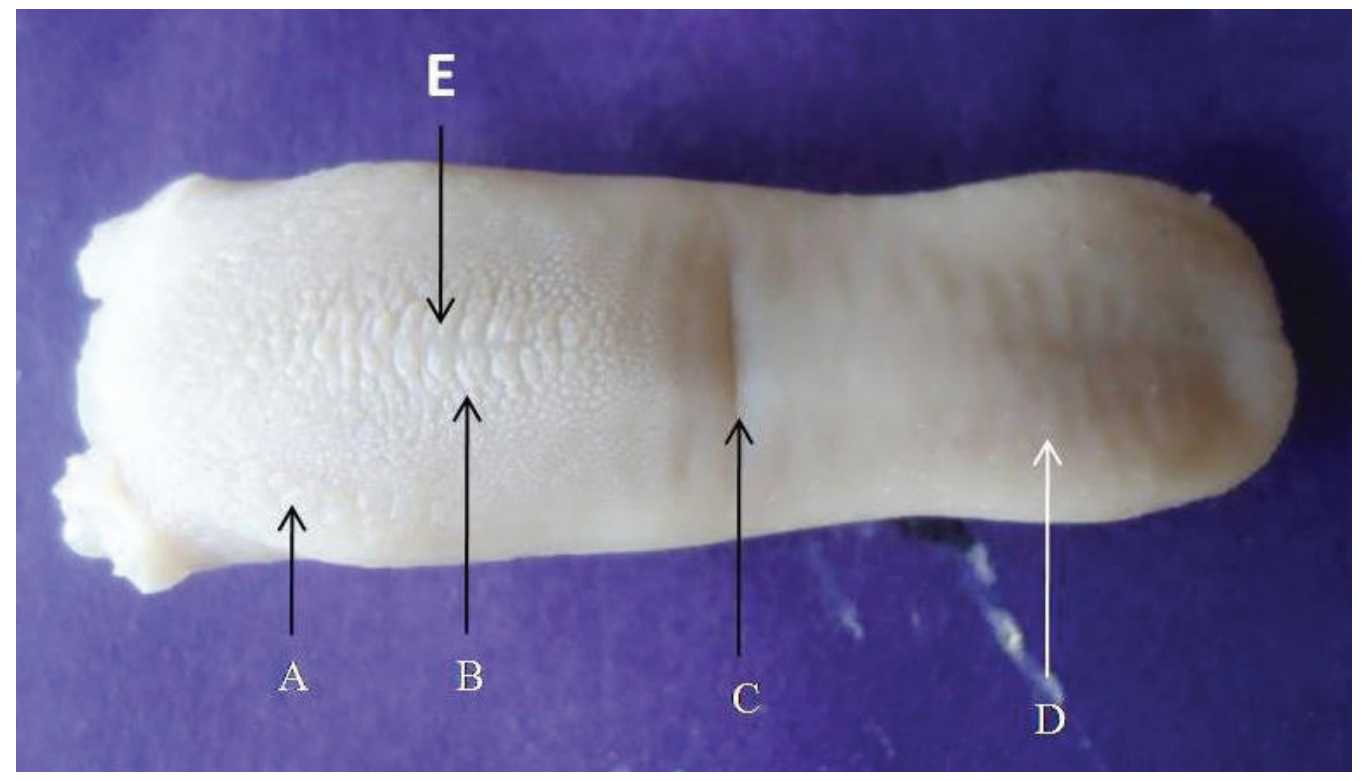

Fig (5): Photograph of tongue at 134 days of gestation showing circumvallate papillae (A), conical papillae (B), lingual fossa (C), fungiform papillae (D), lenticular papillae (E). 